tact Resistance of Carbon and Copper Brushes and the Temperature Rise of the Commutator.' $\mathrm{He}$ finds that the contact resistance decreases with increase of current density, especially with higher velocities of commutator surface; thus, with a velocity of 368 meters (1205 ft.) per minute, the resistance per sq. $\mathrm{cm}$. is for $.7 \mathrm{amp}$. per sq. cm. .6 ohm., while for $10 \mathrm{amp}$. it becomes only .1 ohm., beyond which point it is nearly constant. He finds also that for a given current density the resistance increases with speed to a maximum, and then decreases for higher speeds; this he accounts for by supposing an unfavorable relation between the weight of the brush and the periodicity of the vibrations from passing over the segments; this theory is upheld by the fact that the same maximum appears at a lower speed for the heavier copper brush. A highly polished metal surface gives a higher resistance, which oiling increases still further. He mentions eddy currents as producing losses in the segments, and gives formulæ for the friction losses and the rise of the temperature.

F. C. C.

\section{ENZYMES AS REMEDIES IN INFECTIOUS DISEASES.}

DURING the past year Drs. R. Emmerich and Oscar Loew have been engaged upon an interesting problem in connection with enzymes as remedies in infectious diseases. The work was carried on in Munich, and as yet the results have not been published in full. We are indebted to Dr. Loew for the following facts in regard to the investigations: It has been surmised by Nencki and by Pfeiffer that the substances leading to recovery from infectious diseases, and producing immunity from them, belong to the enzymes. The latter author believed that these enzymes are prepared by the animal organs and not by bacteria themselves. Dr. de Schweinitz has observed an enzyme in cultures of the hog cholera germ which had a potent action in rendering guinea pigs insusceptible to this disease. However, this enzyme exhibited poisonous action in but little higher doses than necessary for immunizing.

Recently Emmerich and Loew have proved that certain kinds of bacteria, for example,
Bacillus pyocyaneus, produce enzymes which not only dissolve these bacilli themselves, but also other microbes, such as the germs of cholera, typhoid fever,' anthrax, diphtheria, black plague, stapthlococci and probably also gonococci. The germs of tuberculosis and many others are not affected by this enzyme within 24 hours. Micrococcus prodigiosus can also produce a bacteriolytic enzyme, which does not ap-


The Misrococcus erysipelatos produces one, but this is associated, as in many other cases, with very poisonous qualities. * Emmerich and Loew have demonstrated that in a rabbit first infected with anthrax and then treated with subcutaneous injections of the concentrated enzyme of the Bacillus pyocyaneus the anthrax bacilli in the spleen are found completely broken up and partly dissolved, exactly as it can be observed in vitro when a dose of millions of anthrax and the other named bacilli are transferred into a few cubic centimeters of the concentrated and purified pyocyaneus enzyme. The latter enzyme can, by combination with an animal protein, be transformed into an immunizing substance. The authors have succeeded in obtaining both these agencies in a durable solid form. Thus the time seems near at hand when the treatment with serum will be replaced by a cheaper and simpler method, at least in certain cases.

\section{B. T. Gallowáy.}

\section{SCIENTIFIC NOTES AND NEWS.}

THE refusal of Congress to establish a permanent census bureau for the proper conduct of the work has had its natural sequence in the appointment of a politician as Director of the Twelfth Census. The best that can be said of ex-Governor Merriam is that he had a creditable record as Governor of Minnesota. The New York Evening Post speaks of the appointment as follows: "Mr. Merriam is appointed Director of the Census simply because there was no other good office vacant at home or abroad. He has never had any experience as

*The bacillus of the black plague, that of tuberculosis, and other kinds, seem incapable of producing bacteriolytic enzymes, at least not to any noticeable degree, and the serum of black plague has, therefore, been applied without success in the cases at Vienna. 